\title{
Quiz: Electrocardiogram
}

\section{Presentation}

Female, 78 years old, complains on weakness, dizziness, loss of consciousness several times during last week.

Fragment of electrocardiogram (ECG) was recorded using 3 leads Holter monitor at the evening during the rest (Fig.1.).

Speed of the recording $-25 \mathrm{~mm} / \mathrm{s}$.
The correct description of this ECG is:
A) Atrioventricular (AV) block I degree
B) AV block II degree, Wenckebach
C) AV block II degree, 2:1
D) AV block II degree, Mobitz
E) AV block II degree, advanced
F) AV block III degree, complete

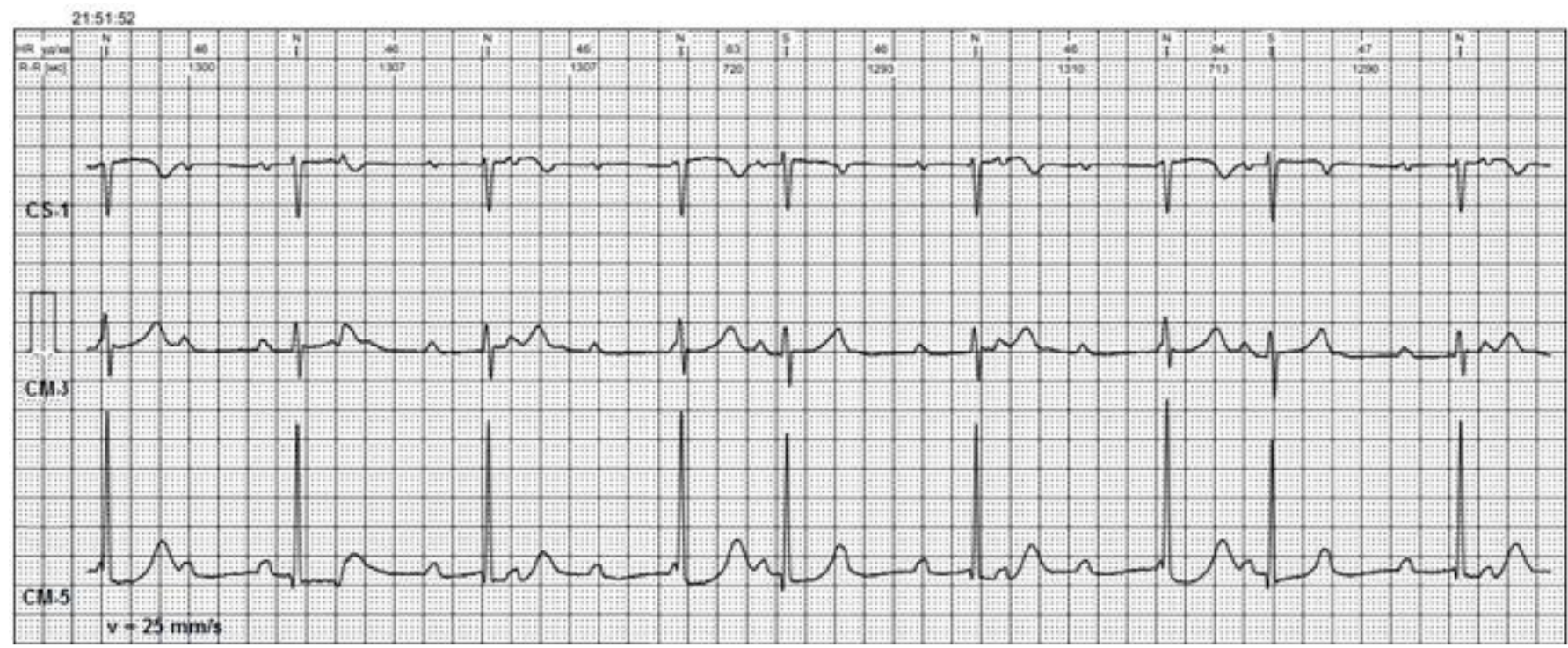

Figure1. Fragment of the 3-channel Holter monitoring

Mykhaylo Sorokivskyy, Ulyana Chernyaha-Royko Danylo Halytsky Lviv National Medical University, Lviv Regional Cardiology Center, Lviv, Ukraine Peer-review: internal Conflict of interest: None to declare Authorship: M.S. and U.C-R. equally contributed to preparation of quiz Acknowledgement and funding: None to declare

Address for Correspondence: Mykhaylo Sorokivskyy, Danylo Halytsky Lviv National Medical University, Lviv Regional Cardiology Center, Lviv, Ukraine; Email: msorokivskyy1@gmail.com

Received: 14.10.2019 Accepted: 15.10.2019

Copyright@ 2019 Heart, Vessels and Transplantation

doi: $10.24969 /$ hvt.2019.161 